PREPARED FOR SUBMISSION TO JINST

$15^{\text {Th }}$ Workshop on Resistive Plate Chambers and Related detectors

10-14 FEBruary 2020

ROME

\title{
Characterization of new eco friendly gas mixtures based on HFO for RPCs
}

\author{
G. Proto, ${ }^{a, b, 1}$ G. Aielli, ${ }^{a, b}$ E. Alunno Camelia, ${ }^{a, b}$ P. Camarri, ${ }^{a}$ R. Cardarelli, ${ }^{b}$ A. Di Ciaccio,,${ }^{a, b}$ \\ L. Di Stante, ${ }^{a}$ B. Liberti, ${ }^{b}$ A. Paoloni, ${ }^{c}$ E. Pastori, ${ }^{b}$ L. Pizzimento, ${ }^{b}$ A. Rocchi, ${ }^{b}$ R. \\ Santonico, ${ }^{a, b}$ E. Tusi ${ }^{a}$ \\ ${ }^{a}$ University of Rome Tor Vergata, \\ Via della Ricerca Scientifica 1, Rome, Italy \\ ${ }^{b}$ INFN Rome Tor Vergata, \\ Via della Ricerca Scientifica 1, Rome, Italy \\ ${ }^{c}$ INFN Laboratori Nazionali di Frascati (LNF), \\ Via Enrico Fermi, 54, Italy \\ E-mail: giorgia.proto@roma2.infn.it
}

AвstRACT: The ATLAS RPC standard mixture, mainly based on $\mathrm{C}_{2} \mathrm{H}_{2} \mathrm{~F}_{4}$, has a high Global Warming Potential (GWP) and therefore the search for RPC eco friendly gases is mandatory. In this work we present the results on the detector performances in terms of efficiency, prompt and ionic charge, with different gas mixtures.

Keywords: Resistive-plate chambers, Gaseous detectors

${ }^{1}$ Corresponding author. 


\section{Contents}

1 Introduction 1

2 Experimental setup 2

3 Analysis Parameters Definition 2

4 Measurements Strategy and Experimental Results 3

4.1 Mixtures with HFO1234ze/CO $/ \mathrm{i}-\mathrm{C}_{4} \mathrm{H}_{10} / \mathrm{SF}_{6} \quad 3$

4.1.1 Performance with $\mathrm{HFO} 1234 \mathrm{ze} / \mathrm{i}-\mathrm{C}_{4} \mathrm{H}_{10}$ variable ratio 4

4.1.2 Performance with $\mathrm{HFO} 1234 \mathrm{ze} / \mathrm{CO}_{2}$ variable ratio 5

4.2 Mixtures with $\mathrm{HFO} 1233 \mathrm{zd} / \mathrm{CO}_{2} / \mathrm{i}-\mathrm{C}_{4} \mathrm{H}_{10} / \mathrm{SF}_{6}$

$\begin{array}{lll}\text { 4.2.1 Performance with mixtures with and without } \mathrm{SF}_{6} & 6\end{array}$

$\begin{array}{llr}5 & \text { Conclusions } & 8\end{array}$

\section{Introduction}

The RPC standard mixture, composed by $\mathrm{C}_{2} \mathrm{H}_{2} \mathrm{~F}_{4} / \mathrm{i}-\mathrm{C}_{4} \mathrm{H}_{10} / \mathrm{SF}_{6} /=94.5 / 5 / 0.5$, is presently used in several experiments with a high radiation environment. Unfortunately it has a high Global Warming Potential of about 1490 , mainly due to the $\mathrm{C}_{2} \mathrm{H}_{2} \mathrm{~F}_{4}\left(\mathrm{SF}_{6}\right.$ gives a minor contribution of $\left.\sim 90\right)$. The use of this mixture could be problematic in the near future if additional restrictions on the greenhouse gas emissions will be imposed.

The main problem in searching for alternative mixtures is to maintain good avalanche saturation properties and the separation between avalanche operation mode and streamer contamination over a large electric field range $(\sim 1 \mathrm{kV})$.

For what concerns the new generation of RPCs that are planned for the LHC upgrade, the new detector layout together with the development of new Front-End electronics give the possibility to work with new mixtures with lower GWP [1-5], based on $\mathrm{HFO}, \mathrm{CO}_{2}, \mathrm{i}_{-} \mathrm{C}_{4} \mathrm{H}_{10}$ and $\mathrm{SF}_{6}$. Instead the RPCs already installed in the experiment that can't be upgraded, can not work with these new mixtures.

With HFO-based new gas mixtures, the avalanches are wider and carry more charge and the transition to streamers passes through multi-avalanches events with a high charge content. The charge distributions are broader and the saturated-avalanche regime is achieved only when the efficiency is still too low.

The goal of this study is to identify the best new mixture and to optimize the percentages of the various component inside the mixture. 


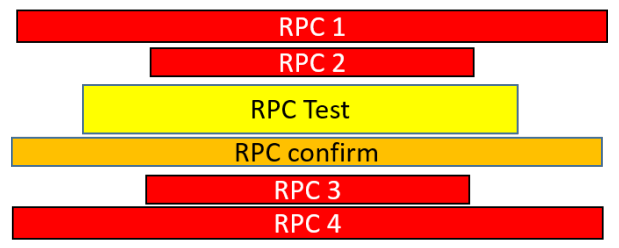

Figure 1: Schematic view of the experimental setup.

\section{Experimental setup}

A schematic view of the experimental setup is shown in Figure 1.

An RPC with $2 \mathrm{~mm}$ gas gap and two $1.8 \mathrm{~mm}$ thick electrodes (ATLAS-like) has been used in this test. The detector dimensions are $57 \times 10 \mathrm{~cm}^{2}$. The prompt induced signal is read out on both sides of a single strip line with the oscilloscope without signal amplification. One of the two signals is acquired with the maximum sensibility of the oscilloscope to optimize the analysis for the avalanche, while the other is acquired with a variable scale to study the streamers. The oscilloscope has a bandwidth of $3 \mathrm{GHz}$ and a sampling velocity of $20 \mathrm{Gs} / \mathrm{s}$ and the time window acquired for the prompt signal is $200 \mathrm{~ns}$.

The ionic signal is read out on a resistance of about $10 \mathrm{k} \Omega$ on the ground graphite electrode over a time window of $100 \mu \mathrm{s}$.

The trigger system consists in four RPCs (see Figure 1) and a $1 \mathrm{~mm}$ gas gap RPC has been used as time reference and confirmation for the efficiency measurement.

\section{Analysis Parameters Definition}

A signal is considered efficient if it crosses an amplitude threshold, defined as the $5^{*} \mathrm{RMS}$ of the background amplitude distribution which is measured in a time window of 20 ns just before the trigger signal. No Front-End electronics has been used, and the lowest equivalent threshold is $2.2 \mathrm{mV}$ ( highest oscilloscope sensitivity), which is substantially higher than the one of the ATLAS RPCs $(\sim 1.2 \mathrm{mV})$.

The avalanche charge, the total prompt charge and the ionic charge are measured for each acquired waveform. The avalanche charge is defined as the integrated charge in $10 \mathrm{~ns}$ around the first peak. The total prompt charge is the integrated charge in the whole time window of $180 \mathrm{~ns}$ (the first $20 \mathrm{~ns}$ are used for the background measurement), so it includes also the multi-avalanches and the streamers contributions. The ionic charge is measured in the full time window of $80 \mu \mathrm{s}$ after trigger. The window of $20 \mu$ s before the trigger has been used for the background measurement.

The delivered charge in HFO-based mixtures takes an important contribution from multi-avalanches, therefore, instead of streamer, we prefer to define an extra-charge, due to all signals observed in $180 \mathrm{~ns}$. A threshold of $20 \mathrm{pC}$ has been fixed to discriminate what we call an extra-charge event. This parameter includes the contributions of multi-avalanches signals, very wide avalanches and streamers. 


\section{Measurements Strategy and Experimental Results}

In order to study the properties of the different gas components, a series of measurements have been performed starting from the mixture composed by $\mathrm{C}_{3} \mathrm{H}_{2} \mathrm{~F}_{4}(\mathrm{HFO}-1234 \mathrm{ze}) / \mathrm{CO}_{2} / \mathrm{i}-\mathrm{C}_{4} \mathrm{H}_{10} / \mathrm{SF}_{6}=38 /$ 56/5/1. In the first series the $\mathrm{CO}_{2} / \mathrm{SF}_{6}$ ratio has been kept constant, while $\mathrm{HFO} / \mathrm{i}-\mathrm{C}_{4} \mathrm{H}_{10}$ percentages have been changed. In the second series the $\mathrm{i}-\mathrm{C}_{4} \mathrm{H}_{10} / \mathrm{SF}_{6}$ fraction is fixed and the percentages of the main components of the mixture vary.

Finally, a different new type of $\mathrm{HFO}, \mathrm{C}_{3} \mathrm{H}_{2} \mathrm{ClF}_{3}$ (HFO-1233zd), has been tested. The performance of each gas mixture has been studied in terms of efficiency, avalanche-extra charge separation and total charge delivered in the detector together with the ionic/prompt charge ratio. For all measurements the standard mixture has been kept as a reference. In Figure 2 the results for the standard mixture are summarized.

The efficiency curve shows that the voltage gap between the efficiency plateau and the streamer appearance is of $\sim 1 \mathrm{kV}$ (Figure 2.a top). The ionic to prompt charge ratio as a function of the ionic charge reaches at $10 \mathrm{kV}$ (efficiency plateau) the constant value of 8, for an average ionic charge value of $\sim 11 \mathrm{pC}$ (Figure 2.b). All the high voltage points are considered in the measurement of the ionic and prompt charge.

\section{Standard Mixture}

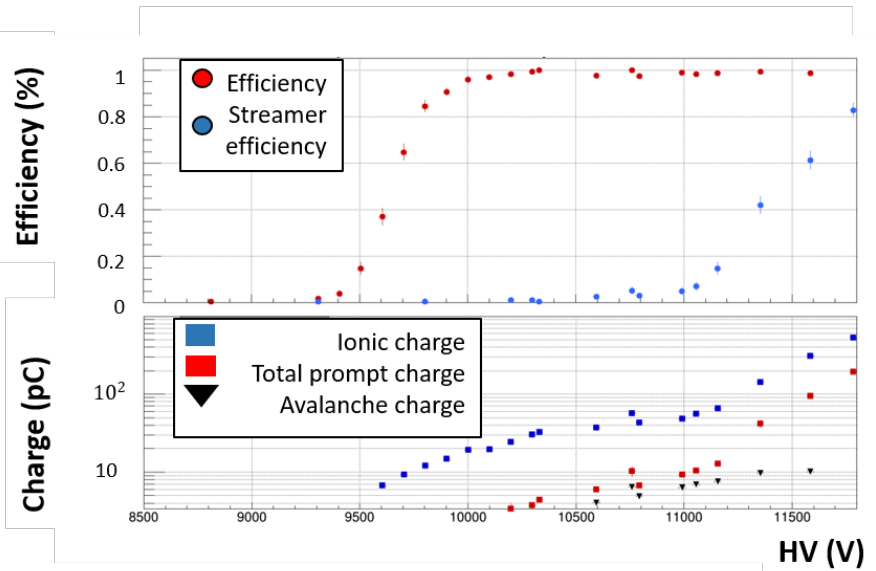

a)

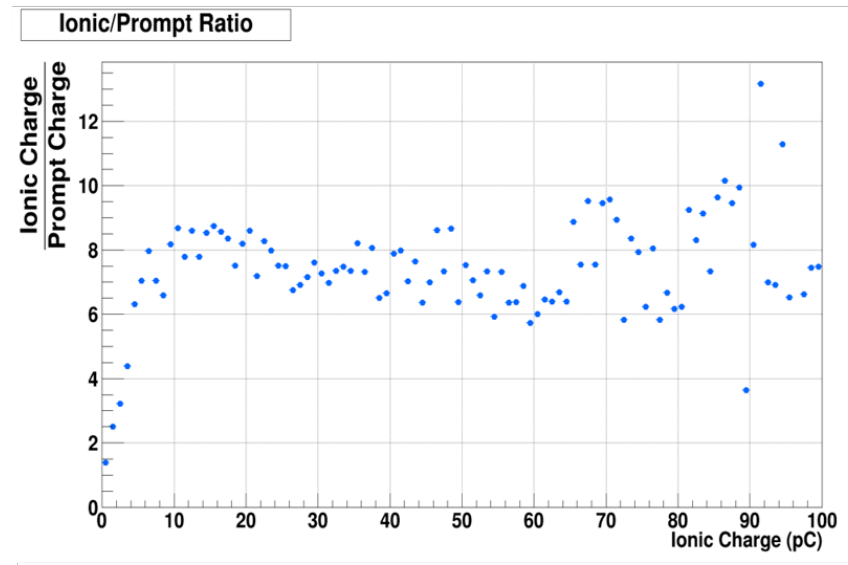

b)

Figure 2: Standard Mixture results. a-top) Efficiency (red) and Streamer probability (blue) as a function of the high voltage. a-bottom) Ionic charge (blue), total prompt charge (red) and avalanche charge (blue) as a function of the high voltage. b) Ionic/prompt ratio as a function of the ionic charge

\subsection{Mixtures with $\mathrm{HFO1234ze} / \mathrm{CO}_{2} / \mathrm{i}-\mathrm{C}_{4} \mathrm{H}_{10} / \mathrm{SF}_{6}$}

The first measurment has been performed with the mixture composed by $\mathrm{HFO} 1234 \mathrm{ze} / \mathrm{CO}_{2} / \mathrm{i}$ $\mathrm{C}_{4} \mathrm{H}_{10} / \mathrm{SF}_{6}=38 / 56 / 5 / 1$, with the $\mathrm{CO}_{2}$ as the main component.

In general we would like to work with as much $\mathrm{CO}_{2}$ as possible, because the HFO plays the role of 
quencher and it moves the working point towards very high voltages. A greater fraction of HFO is expected to show lower extra charge probability and lower current flowing inside the detector.

Two sets of measurements have been performed, one to study the quenching components and the other to study the ratio between the main components of the mixture.

\subsubsection{Performance with $\mathrm{HFO1234ze/} \mathrm{i}-\mathrm{C}_{4} \mathrm{H}_{10}$ variable ratio}

In this section the $\mathrm{CO}_{2}$ and $\mathrm{SF}_{6}$ concentrations are fixed at the ratio 56/1, while the $\mathrm{HFO}$ percentage is lowered in favour of $\mathrm{i}-\mathrm{C}_{4} \mathrm{H}_{10}$. Three mixtures are studied: $\mathrm{HFO} / \mathrm{i}-\mathrm{C}_{4} \mathrm{H}_{10}=38 / 5,33 / 10,29 / 14$. The results are reported in Figure 3.

We can notice that the addition of $10 \%$ of $\mathrm{i}-\mathrm{C}_{4} \mathrm{H}_{10}$ lowers the operating voltage of about $600 \mathrm{~V}$
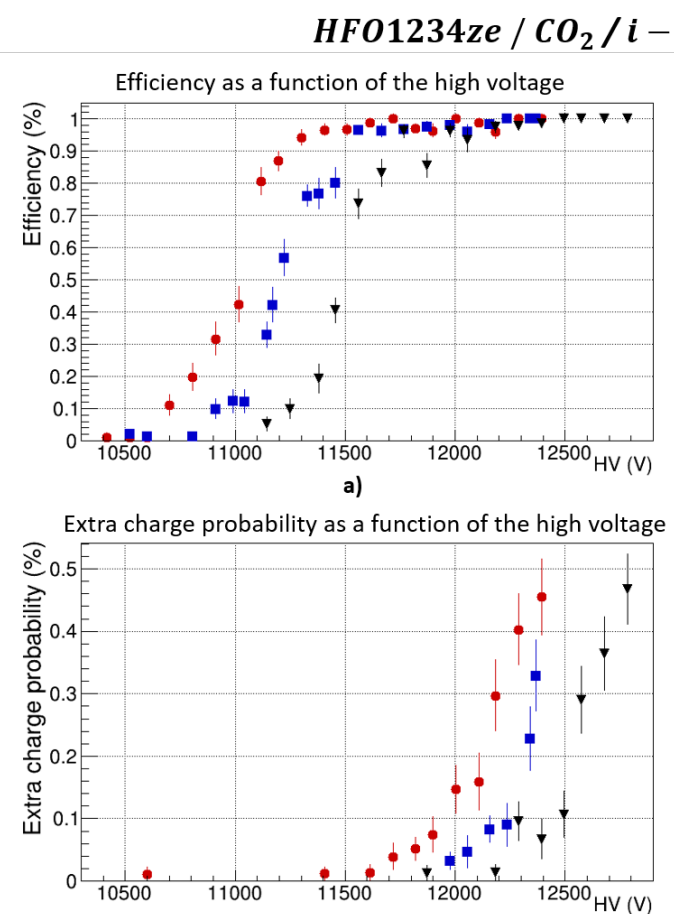

b)
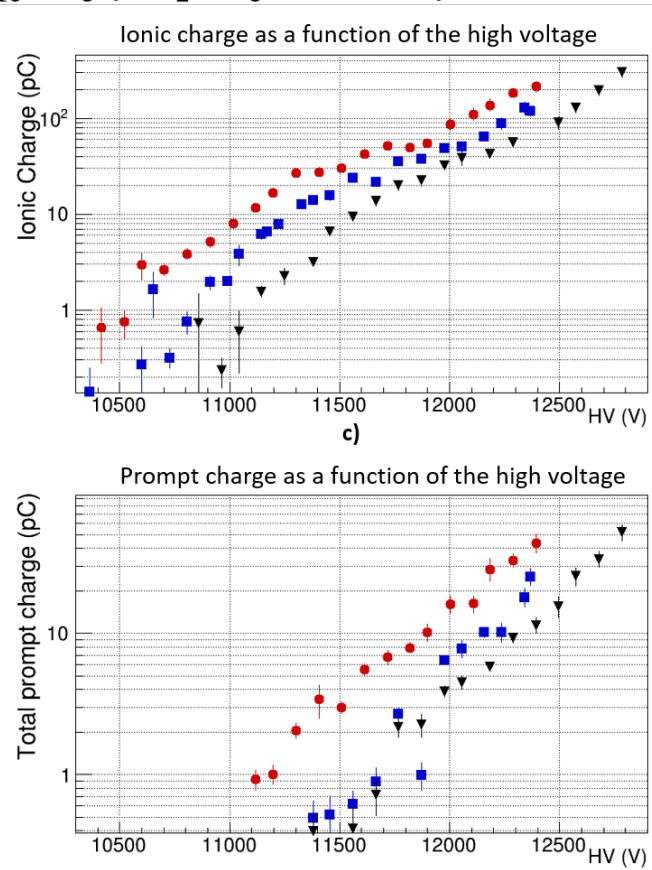

d)

$$
H F O / i-C_{4} H_{10}=29 / 14 \quad \text { aFO/i }-C_{4} H_{10}=33 / 10 \quad \nabla H F O / i-C_{4} H_{10}=38 / 5
$$

Figure 3: Efficiency (a), extra charge probability (b), ionic charge (c) and total prompt charge (d) as a function of the high voltage at fixed $56 / 1 \mathrm{CO}_{2} / \mathrm{SF}_{6}$ ratio for the three mixtures: $\mathrm{HFO} / \mathrm{i}-\mathrm{C}_{4} \mathrm{H}_{10}=$ 29/14 (red points), 33/10 (blue squares) and 38/5 (black triangles).

and the avalanche-extra charge separation is $\sim 600 \mathrm{~V}$ for all the three mixtures (Figure 3.a-3.b). If we look at the total prompt charge we can see that the average value is the same $(\sim 4 \mathrm{pC})$ for the three mixtures at the respective working points (Figure 3.d). The same happens for the ionic charge, which represents the total charge delivered inside the detector and takes the value of $\sim 30 \mathrm{pC}$ at the respective working points (Figure 3.c).

In conclusion there is no effect in increasing $\mathrm{i}-\mathrm{C}_{4} \mathrm{H}_{10}$ in terms of avalanche-extra charge separation and total charge delivered at the working point, but only in terms of operating voltage which is lower in the mixture with less HFO. 


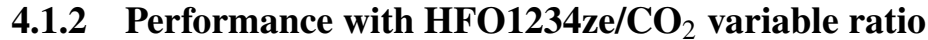

In this section the fraction $\mathrm{i}-\mathrm{C}_{4} \mathrm{H}_{10} / \mathrm{SF}_{6}$ has been kept constant to the ratio $5 / 1$ and the concentration of $\mathrm{CO}_{2}$ has been increased in steps of 5\%. The reported $\mathrm{HFO} / \mathrm{CO}_{2}$ ratios are 38/56, 33/61 and 28/66.

In Figure 4 the results are reported. It can be seen that the reduction of HFO moves the working point to lower voltages of about $400 \mathrm{~V}$ every $5 \%$ of HFO reduction (Figure 4.a). The total prompt charges for the three gas mixtures at the working point are consistent with each other $(\sim 3 \mathrm{pC})$ but the total ionic charge is higher in the mixture with more HFO $(\sim 30 \mathrm{pC}$ against $\sim 20 \mathrm{pC}$ for the other two) as you can see in Figures 4.c-4.d.

For what concerns the avalanche-extra charge separation, the range is larger in the mixture with more HFO (Figure 4.b).

$\mathrm{HFO1234ze} / \mathrm{CO}_{2} / \mathrm{i}-\mathrm{C}_{4} \mathrm{H}_{10} / \mathrm{SF}_{6}\left(\mathrm{i}-\mathrm{C}_{4} \mathrm{H}_{10} / \mathrm{SF}_{6}\right.$ ratio = 5/1)
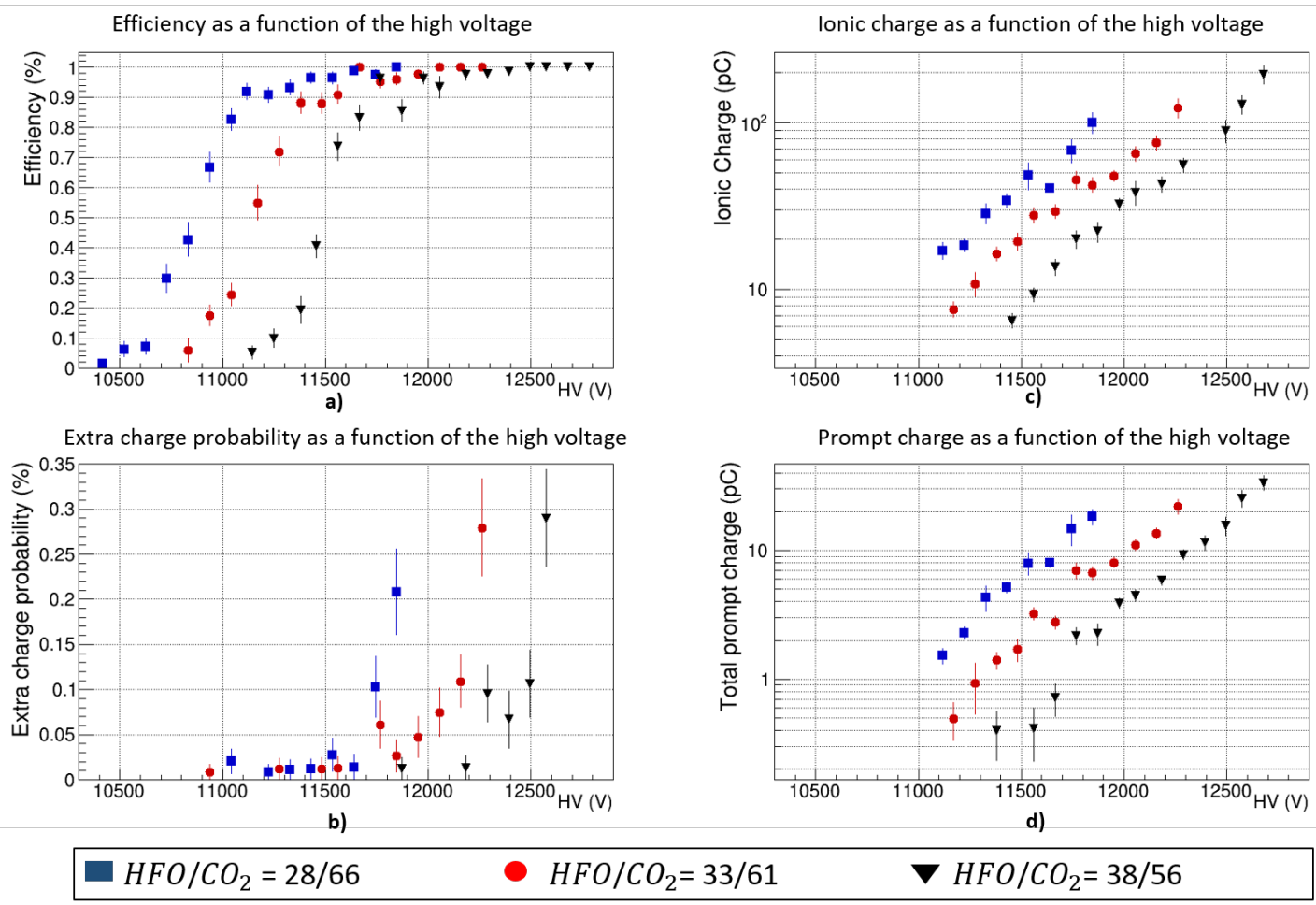

Figure 4: Efficiency (a), extra charge probability (b), ionic charge (c) and total prompt charge (d) as a function of the high voltage at fixed $5 / 1 \mathrm{i}-\mathrm{C}_{4} \mathrm{H}_{10} / \mathrm{SF}_{6}$ ratio for the three mixtures: $\mathrm{HFO} / \mathrm{CO}_{2}=$ 28/66 (blue squares), 33/61 (red points) and 38/56 (black triangles).

\subsection{Mixtures with $\mathrm{HFO1233zd} / \mathrm{CO}_{2} / \mathbf{i}-\mathrm{C}_{4} \mathrm{H}_{10} / \mathrm{SF}_{6}$}

In this section the results related to a different type of HFO, the HFO1233zd [6], are reported. This molecule, $\mathrm{C}_{3} \mathrm{H}_{2} \mathrm{ClF}_{3}$, has an extra Chlorine respect to the previous one and one Fluorine less. Similar molecules containing two different halogen atoms, were already tested as RPC gas components. $\mathrm{CF}_{3} \mathrm{Br}$ was shown to have a relevant effect in reducing the streamer size in RPC operating in 
streamer mode [12]. Moreover, the pure avalanche mode without any streamer contamination was first observed in RPCs filled with pure $\mathrm{CF}_{3} \mathrm{Br}$. More recently, the $\mathrm{CF}_{3} \mathrm{I}$ molecule was successfully tested as an alternative RPC gas [4]. Unfortunately, none of these molecules is suitable for very large size RPC systems, where industrial gases are needed. Indeed $\mathrm{CF}_{3} \mathrm{Br}$ has a very high ozone depletion potential and $\mathrm{CF}_{3} \mathrm{I}$ is very poisonous.

$\mathrm{C}_{3} \mathrm{H}_{2} \mathrm{ClF}_{3}$ is an industrial gas and does not have the above problems and the test made with the other two-halogen molecules suggests that it could be suitable to suppress the streamer appearance and to keep the avalanche size to modest values. Moreover the quenching power of this gas, HFO 1233zd, is expected to be stronger than that of HFO-1234ze. The properties of this gas suggest that it might replace the $\mathrm{SF}_{6}$.

A test with a new gas mixture composed by HFO- $1233 \mathrm{zd} / \mathrm{CO}_{2} / \mathrm{i}-\mathrm{C}_{4} \mathrm{H}_{10}$ without the presence of $\mathrm{SF}_{6}$ has been performed, in order to study if this gas could give the same benefits of the $\mathrm{SF}_{6}$.

\subsubsection{Performance with mixtures with and without $\mathrm{SF}_{6}$}

The mixtures under study are composed by HFO- $1233 \mathrm{zd} / \mathrm{CO}_{2} / \mathrm{i}-\mathrm{C}_{4} \mathrm{H}_{10}=15 / 80 / 5$ with and without the addition of $1 \%$ of $\mathrm{SF}_{6}$. The experimental results are reported in Figure 5.

It can be seen that the mixture without $\mathrm{SF}_{6}$ has an operating voltage $\sim 300-400 \mathrm{~V}$ (at $90 \%$ efficiency) lower and shows a steeper rise. This is an expected behaviour [9] and can be explained with the very high electronegativity of this molecule. In fact the simultaneous presence of the $\mathrm{HFO}$ and $\mathrm{SF}_{6}$ breaks the avalanche growth and makes harder the rise of the efficiency curve.

The total prompt charge at the plateau knee $(11800 \mathrm{~V}$ and $12100 \mathrm{~V})$ is higher in the mixture with the $\mathrm{SF}_{6}(\sim 6 \mathrm{pC}$ against $8 \mathrm{pC})$ and the same is true for the ionic charge delivered in the detector $(\sim 40 \mathrm{pC}$ against $60 \mathrm{pC}$ ). Therefore, when $\mathrm{SF}_{6}$ is added, it finds a very electronegative environment and the resulting effect is the premature break of the avalanche growth and not the streamers suppression. In Figure 6 the ionic/prompt charge ratio as a function of the ionic charge is shown.

The ratio is $\sim 8$ at the mean value of the ionic charge at the operating voltage as in the standard mixture, but this plateau value is reached only when the extra charge events occur. In addition, even if the ratio has the same value for both mixtures, the mean value of the two charges is twice in the HFO-based mixture.

Figure 7 shows the comparison between the total prompt charge distributions of the standard mixture and the $\mathrm{HFO} 1233 \mathrm{zd} / \mathrm{CO}_{2} / \mathrm{i}-\mathrm{C}_{4} \mathrm{H}_{10}$ mixture at different values of the efficiency.

At lower efficiency the two distributions are concentrated near the ideal line which separate the signal charge and the background charge. When efficiency rises the total prompt charge distribution for the standard mixture shows the typical trend of saturated avalanche regime, on the opposite the HFO mixture has a broader distribution, causing an higher average working prompt charge value (see Figure 7). 
$\mathrm{HFO1233zd} / \mathrm{CO}_{2} / \mathrm{i}-\mathrm{C}_{4} \mathrm{H}_{10}$ with and without $\mathrm{SF}_{6}$
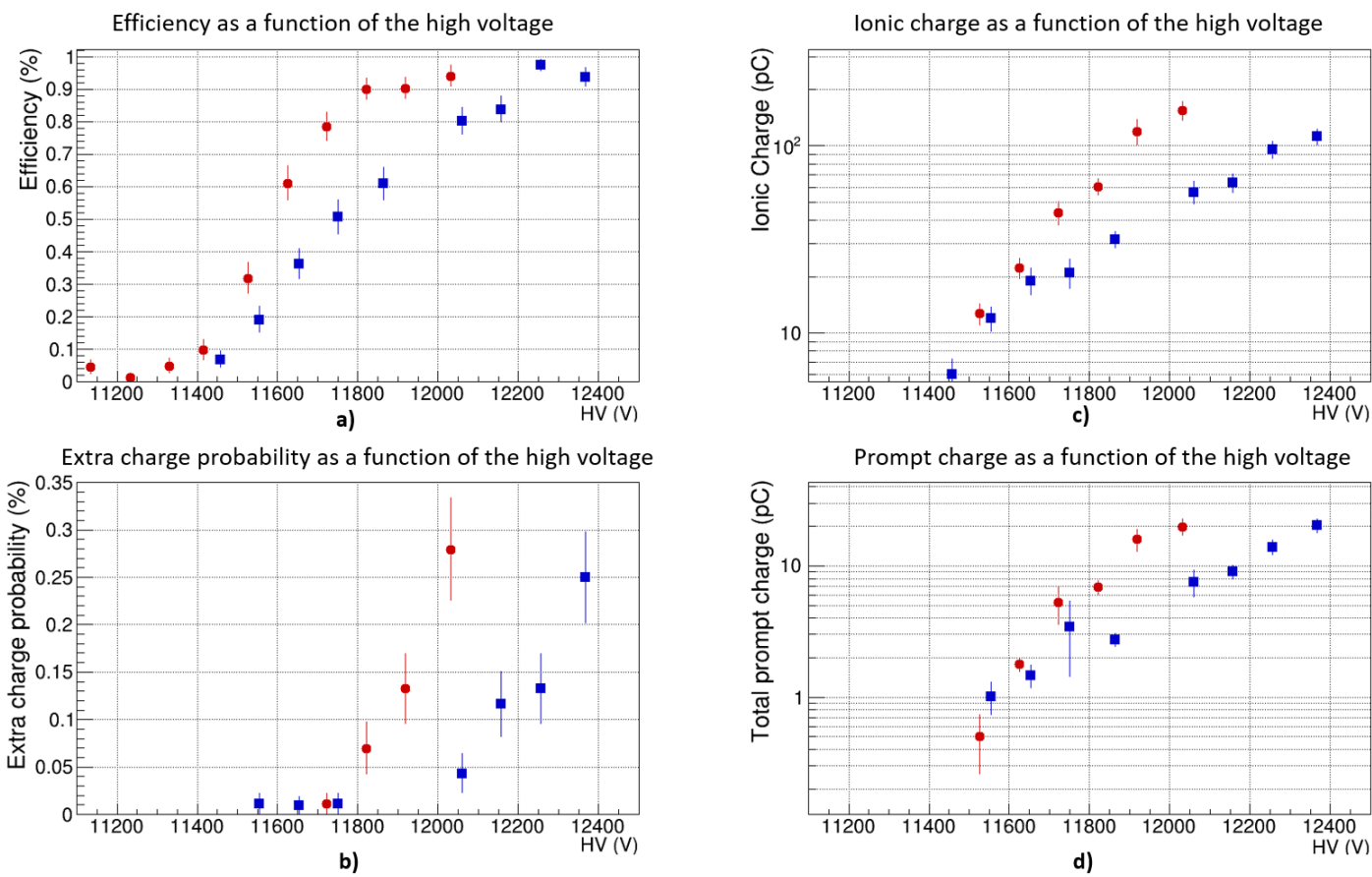

Without $S F_{6}$

With $S F_{6}$

Figure 5: Efficiency (a), extra charge probability (b), ionic charge (c) and total prompt charge (d) as a function of the high voltage for the two mixtures: $\mathrm{HFO} 1233 \mathrm{zd} / \mathrm{CO}_{2} / \mathrm{i}-\mathrm{C}_{4} \mathrm{H}_{10}$ without $\mathrm{SF}_{6}$ (red points) and with $\mathrm{SF}_{6}$ (blue squares).

$\mathrm{HFO1233zd} / \mathrm{CO}_{2} / \mathrm{C}_{4} \mathrm{H}_{10}$

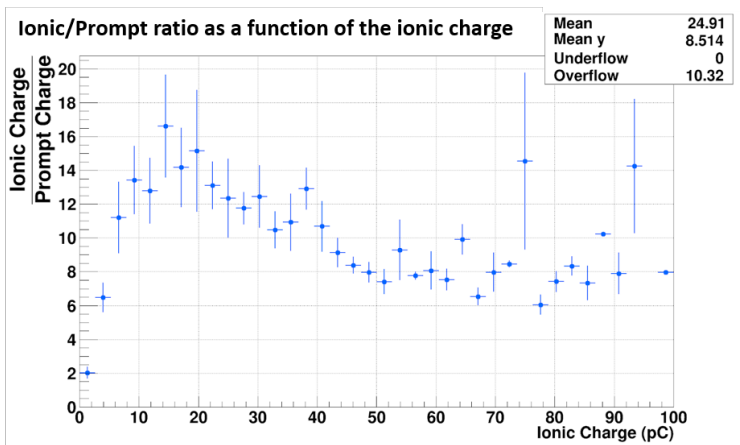

Figure 6: Ionic/Prompt ratio as a function of the ionic charge for the $\mathrm{HFO} 1233 \mathrm{zd} / \mathrm{CO}_{2} / \mathrm{i}$-Butane Mixture . 


\section{HFO1233zd/ $\mathrm{CO}_{2} / \mathrm{C}_{4} \mathrm{H}_{10}$ and standard mixture charge distributions}

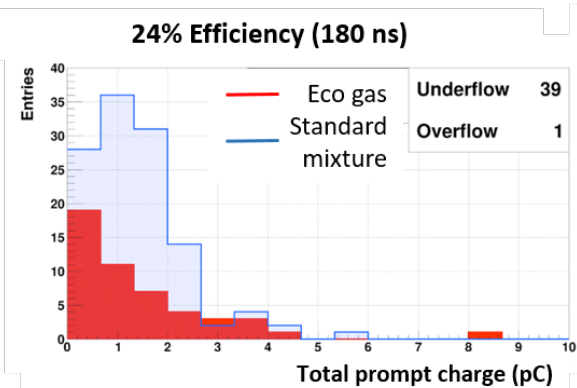

a)

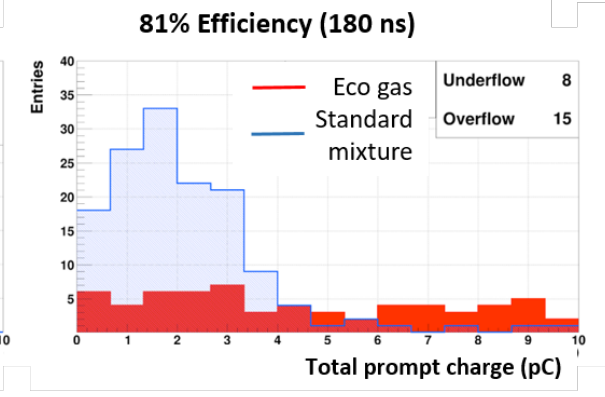

b)

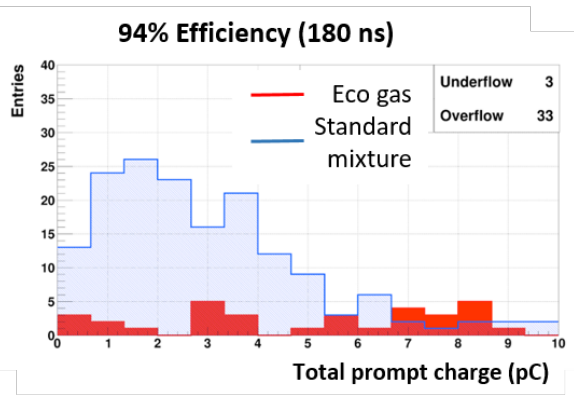

c)

Figure 7: Total prompt charge distribution at 24\% (a), $81 \%$ (b) and $94 \%$ (c) of efficiency for the standard mixture (blue) and $\mathrm{HFO} 1233 \mathrm{zd} / \mathrm{CO}_{2} / \mathrm{i}-\mathrm{Butane}$ Mixture (red).

\section{Conclusions}

In this work we made a systematic performance study of a small size RPC filled with four gas mixture components $\mathrm{C}_{3} \mathrm{H}_{2} \mathrm{~F}_{4}(\mathrm{HFO} 1234 \mathrm{ze}) / \mathrm{CO}_{2} / \mathrm{i}-\mathrm{C}_{4} \mathrm{H}_{10} / \mathrm{SF}_{6}$, using the following different proportions among them: 29/56/14/1,33/56/10/1, 38/56/5/1, 28/66/5/1 and 33/61/5/1. We obtained the following results:

- Decreasing $\mathrm{i}-\mathrm{C}_{4} \mathrm{H}_{10}$ in the $\mathrm{HFO} / \mathrm{i}-\mathrm{Butane}$ ratio produces a decrease of the operating voltage of about $\sim 600 \mathrm{~V}$ but does not change the delivered charge, which is the same in the three mixtures and has a value of $\sim 30 \mathrm{pC}$. Also the avalanche- extra charge separation is the same in the three mixtures;

- Decreasing the $\mathrm{HFO}$ in the $\mathrm{HFO} / \mathrm{CO}_{2}$ ratio has the effect to decrease both the operating voltage and the delivered charge. The voltage decrease is $\sim 800 \mathrm{~V}$ and the delivered charge decrease is $\sim 10 \mathrm{pC}$. This suggests that HFO concentration should be lowered below the $28 \%$ value tested in this study. The avalanche-extra charge separation range is larger in the mixture with more HFO;

We tested also another HFO gas, $\mathrm{C}_{3} \mathrm{H}_{2} \mathrm{ClF}_{3}$ (HFO1233zd), that has never tested before. This new component has much stronger quenching power than the previous HFO and this suggests that it might replace the $\mathrm{SF}_{6}$. However this possibility requires more studies. 


\section{References}

[1] B. Liberti et al., Further gas mixtures with low environment impact, Journal of Instrumentation 11(09):C09012 (2016).

[2] L. Benussi et al., Properties of potential eco-friendly gas replacements for particle detectors in high-energy physics, Journal of Instrumentation 13.03: P03012 (2018).

[3] R. Guida, M. CapÃlans-Garrido, and B. Mandelli, , Characterization of RPC operation with new environmental friendly mixtures for LHC application and beyond, , Journal of Instrumentation 11(07):C07016 (2016).

[4] M. Abbrescia et al., Eco-friendly gas mixtures for Resistive Plate Chambers based on tetrafluoropropene and helium, Journal of Instrumentation, 11(08):P08019âĂŞP08019 (2016).

[5] R. Cardarelli et al., New RPC gas mixtures for large area apparatuses., Journal of Instrumentation 9(11):C11003 (2014).

[6] National Center for Biotecgnology Information. PubChem Database. CID=5709018, https://pubchem.ncbi.nlm.nih.gov/compound/E_-1-chloro-3_3_3-trifluoroprop-1-ene

[7] R.Santonico and R.Cardarelli, Nucl.Instr.And Meth, 187 (1981).

[8] G.Aielli et al., Saturated logistic avalanche model, Nucl.Instr.And Meth 508, 6-13 (2003).

[9] P. Camarri et al., Streamer suppression with SF6 in RPCs operated in avalanche mode, Nucl.Instr.And Meth 414, 317-324 (1998).

[10] R. Cardarelli, V. Makeev and R. Santonico, Avalanche and streamer mode operation of resistive plate chambers, Nucl.Instr.And Meth 382, 470-474 (1996).

[11] R. Cardarelli, R. Santonico, and V. Makeev. The avalanche to streamer transition in RPCs. report done at III Workshop on RPC and Related Detectors, Pavia 11-12 oct. 1995.

[12] R. Cardarelli, A. Di Ciaccio, R. Santonico Performance of a resistive plate chamber operating with pure CF3Br. Nucl.Instr.And Meth 333, 399-403 (1993).

[13] B. Liberti, RPCs as ATLAS Trigger detectors at LHC, Tesi di Dottorato (1998-1999). 